\title{
Autismo e inclusão na educação infantil: Crenças e autoeficácia da educadora
}

Cláudia Sanini. Universidade Federal do Rio Grande do Sul.

Cleonice Alves Bosa. Universidade Federal do Rio Grande do Sul.

\section{Resumo}

Nesse estudo foram investigadas as crenças de uma educadora sobre o desenvolvimento de seu aluno com autismo, na educação infantil; a confiança no seu trabalho como educadora (senso de autoeficácia) e que aspectos da relação professor-aluno repercutiram na prática pedagógica utilizada. Foi utilizada uma entrevista, que foi gravada, transcrita e submetida à análise de conteúdo. Os resultados mostraram que a aceitação e o reconhecimento do potencial do aluno (crenças), por parte da educadora, tenderam a ser determinantes para a sua prática. Entretanto, verificou-se uma baixa expectativa de autoeficácia, evidenciada pela pouca valorização de sua formação acadêmica; sentimentos de insegurança quanto à adequação de sua prática e a necessidade de receber apoio e partilhar as dificuldades. Estes resultados apontam para a necessidade da formação continuada dos professores de educação infantil, sobretudo daqueles que atuam na área do autismo.

Palavras-chave: crenças; autoeficácia; autismo; educação infantil.

\begin{abstract}
Autism and inclusion in childhood education: Teacher's beliefs and sense of self-efficacy

Autism, inclusion and teacher's beliefs. The aim of this study was to investigate the beliefs of a teacher regarding her student with autism's development, in early childhood education. Also the belief in her work as an educator (sense of self-efficacy) and what aspects of teacher-student relationship reverberated used in pedagogical practice. An interview was conducted with the teacher, which was recorded and transcribed for analysis according to the Content Analysis criteria. The results showed that teacher's acceptance and recognition of the student's potential (beliefs) tend to be a decisive factor for her practice. However, there was a low expectation of self-efficacy, as evidenced by the low appreciation of her academic training; feelings of uncertainty about the adequacy of her pedagogical practice and need to receive support and share the difficulties. These results point to the need for continued training of preschool teachers, especially those working in the area of autism.
\end{abstract}

Keywords: beliefs; self-efficacy; autism; early childhood education.

\section{Resumen}

Autismo y inclusión en la educación infantil: Creencias y autoeficacia del educador

Autismo, inclusión y autoeficacia del educador. En el estudio fueron investigadas las creencias de una educadora sobre el desarrollo de su alumno con autismo, en la educación infantil; la confianza en su trabajo como educadora (autoeficacia) y la qué aspectos de la relación profesor-alumno reverberó en la práctica pedagógica utilizada. Fue utilizada una entrevista, que fue grabada, transcrita y sometida a un análisis de contenido. Los resultados mostraron que la aceptación y el reconocimiento del potencial del alumno (creencias), tienden a ser determinantes para su práctica. Sin embargo, se ha verificado la baja expectativa de la autoeficacia, manifestada por la poca valorización de su formación académica; sentimientos de inseguridad hacia la adecuación de su práctica y la necesidad de recibir apoyo y compartir las dificultades. Estos resultados demuestran la necesidad de la formación continuada de los profesores de educación infantil, sobretodo de los que trabajan en la área de autismo.

Palabras clave: creencias; autoeficacia; autismo; educación infantil. 
Crenças e senso de autoeficácia são constructos da Psicologia do Desenvolvimento que podem contribuir para a compreensão dos fatores que influenciam a prática pedagógica do professor, sobretudo na questão da inclusão. Crenças devem ser entendidas como construções da realidade, maneiras de perceber o mundo e seus fenômenos; são resultantes de um processo interativo de interpretação e (re)significação constantes das relações do indivíduo com o seu meio (Barcelos, 2006). Portanto, as crenças são sociais, dinâmicas, contextuais, paradoxais e co-construídas pela experiência. No contexto escolar, as crenças parecem ter uma influência no processo ensino-aprendizagem e são denominadas de "crenças educacionais", pois se caracterizam por ideias, julgamentos e valores a respeito de temas relacionados à educação, que se manifestam, de forma consciente ou não, através da prática pedagógica do professor (Bzuneck \& Sales, 2011; Moreira \& Monteiro, 2010; Scheifer, 2009). As discussões sobre a relação entre crenças e prática pedagógica ganham relevo no contexto das diferenças, especialmente nos casos que mais desafiam a prática do professor, como o autismo, por exemplo.

O Transtorno do Espectro Autista (TEA) caracteriza-se por uma síndrome comportamental que apresenta comprometimentos nas áreas da interação social e da linguagem/comunicação, além da presença de comportamentos repetitivos e estereotipados, [American Psychiatric Association (APA), 2013]. Estes comportamentos podem ser expressos de diferentes formas: na brincadeira, geralmente repetitiva, por carecer de criatividade e espontaneidade; na fala, que pode ser ecolálica, quando presente; e no desenvolvimento motor, comumente caracterizado por repetições de movimentos, involuntários e sem aparente função (e.g. rituais e maneirismos) (Bosa, 2002).

As manifestações das dificuldades no autismo poderão variar de acordo com o nível desenvolvimental e a idade cronológica da criança, entre outros fatores (APA, 2013). Além disso, quanto maior o comprometimento cognitivo, maior a tendência a isolar-se e a não se comunicar (Klin, 2006), pela dificuldade em compreender as interações sociais. No entanto, a ideia de que a criança com autismo não demonstra afeto e é inquestionavelmente distante e não-comunicativa, não tem sido respaldada por evidências empíricas (Bosa, 2002). De fato, estudos têm revelado, por exemplo, a capacidade dessas crianças para desenvolver relações de apego a seus cuidadores e de responder à interação social em diferentes contextos (ver Sanini, Ferreira, Souza, \& Bosa, 2008, para uma revisão; Sanini, Sifuentes, \& Bosa, 2013). Muitas vezes, o desconhecimento sobre as potencialidades e os limites de uma criança com autismo gera descrença acerca do seu desenvolvimento e da sua capacidade de aprendizagem. Isso pode reduzir o investimento em suas potencialidades e reforçar mitos, tais como o de que é uma criança que "vive em um mundo próprio", alheio ao que ocorre ao seu redor (Goldberg, 2002).

De acordo com Bosa (2002), o comportamento social de crianças com autismo, mais do que um isolamento "proposital" parece decorrer, também, dentre outros aspectos, da dificuldade em compreender as intenções das outras pessoas - habilidade conhecida como Teoria da Mente (Baron-Cohen, 1991). O desenvolvimento desta habilidade permite compreender e deduzir o comportamento das outras pessoas em função de suas intenções. A contrapartida disso é a dificuldade da criança com autismo fazer sentido do que os outros pensam, querem e desejam dela. As implicações disso na rotina escolar, por exemplo, são óbvias. Por isso, quanto maior a clareza na comunicação direta com a criança, maior será o seu entendimento social e, consequentemente, maior a sua participação nas atividades (Bosa, 2006; Cardoso \& Fernandes, 2006; Lopes-Herrera \& Almeida, 2008).

Estar ciente destes modos peculiares de se situar no mundo permite aos educadores criar e desenvolver a sua prática, respeitando e compreendendo essas particularidades. Estudos que investigaram as crenças dos professores sobre seus alunos com autismo, na escola comum, demonstram a influência das crenças do professor nesse processo (Cacciari, Lima, \& Bernardi, 2005; Murray, Ruble, Willis, \& Molloy, 2009; Robertson, Chamberlain, \& Kasari, 2003). Por exemplo, no estudo de Robertson et al. (2003), quando a relação entre o professor e seu aluno com autismo era positiva, isto é, baseada na aceitação desse aluno, este tendia a ser mais aceito socialmente por seus colegas, em sala de aula.

Acredita-se que a noção de "aceitação do aluno", por parte do professor, parece depender de vários fatores, tais como: a sua formação, as políticas de inclusão, a concepção de deficiência e de autismo que possui e, também, do tipo de relação que se propõe a estabelecer com o aluno: se com os seus "sintomas" ou com a criança que constitui este aluno. Optar por uma ou outra forma de se relacionar parece fazer diferença no trabalho do professor junto a este aluno. Tal aspecto pode ser verificado no estudo de Cacciari et al. (2005), que analisou o trabalho desenvolvido por uma equipe interdisciplinar de saúde mental junto aos profissionais de educação que 
trabalhavam com inclusão, em instituições regulares de ensino. Neste estudo, uma educadora, que participou do estudo e recebeu o acompanhamento, demonstrou que na relação com sua aluna com autismo o que se sobressaiu foi a suposta patologia da criança, impedindo um trabalho efetivo, baseado nas necessidades da criança e da turma. Desta forma, foi possível observar que as expectativas e as crenças do professor a respeito de seus alunos podem afetar negativamente os seus objetivos junto a eles, comprometendo o processo de ensino-aprendizagem (Musis \& Carvalho, 2010; Sadalla et al., 2005; Silva, 2003).

Outro aspecto igualmente importante, que parece influenciar o trabalho do professor, é o seu senso de autoeficácia. De acordo com Bandura (1977; 1997), a autoeficácia caracteriza-se pela crença de uma pessoa em sua habilidade para desempenhar atividades que possibilitem alcançar o resultado almejado, isto é, quão confiante a pessoa se sente em relação a este trabalho.

Bzuneck e Guimarães (2003) verificaram que o senso de autoeficácia do professor está relacionado à crença na possibilidade de organizar e implementar ações que permitam alcançar resultados acadêmicos, influenciando a motivação e o bem-estar pessoal no seu trabalho. Schwarzer e Hallum (2008) complementam esta ideia ao considerarem a autoeficácia como um recurso pessoal, que pode proteger o professor de experiências de trabalho tensos e estressantes. Isso porque são essas crenças que farão a diferença na forma como a pessoa pensa, sente e age. Ou seja, as expectativas de autoeficácia irão determinar quando iniciar uma ação, quanto esforço será empregado nessa ação e por quanto tempo esse esforço será sustentado frente aos obstáculos e às experiências frustrantes. Uma criança com autismo pode despertar sentimentos de frustração no professor pelas dificuldades de comunicação, resistência à novidade e facilidade com que se desorganiza diante de desafios (Goldberg, 2002; Marocco, 2012). Suas tentativas de participação e interação social nem sempre são facilmente percebidas, seja porque fogem ao convencional ou porque são "tênues", isto é, revelam-se em pequenos detalhes (Marocco, 2012).

Grande parte dos estudos sobre crenças educacionais e de autoeficácia do professor focalizam a experiência deste nas etapas mais avançadas do ensino. Entretanto, é a educação infantil que representa um grande desafio para o professor porque é nessa etapa que geralmente a família recebe o diagnóstico de autismo. Desta forma, é a professora desse nível de ensino quem primeiro deve lidar com o impacto desta experiência.
A educação infantil assinala, naturalmente, o ingresso de toda criança em um grupo social, longe da proteção da família. Isso engendra novas formas de relacionar-se e de comportar-se, ampliando o repertório de experiências da criança, mas também seus medos, assim como os da família. Consequentemente, esse processo, no caso da inclusão, representa um desafio duplo para o professor. De acordo com De Vitta, De Vitta e Monteiro (2010) a educação infantil é importante para o desenvolvimento de qualquer criança, especialmente para aquelas com necessidades educativas especiais, o que inclui o autismo. Há evidências na literatura sobre a importância da educação infantil no desenvolvimento de crianças com autismo. O estudo de Höher-Camargo (2007), por exemplo, que investigou o perfil de competência social de uma criança pré-escolar com autismo, em situação de inclusão escolar, em relação a uma criança com desenvolvimento típico, mostrou evidências de competência social na criança com autismo, já que as diferenças encontradas em relação às crianças decorreram mais em função da menor frequência/intensidade dos comportamentos apresentados pela criança com autismo do que da sua ausência per se. Deste modo, estes estudos apontam para a importância da ampliação das investigações sobre a experiência de professores, alunos e famílias, em situação de inclusão, na área do autismo.

Considerando a aparente relevância teórica dos conceitos da Psicologia do Desenvolvimento aqui apresentados, sobretudo no contexto da inclusão escolar, este estudo teve como objetivo verificar as crenças de uma educadora sobre seu aluno com autismo, na educação infantil e o seu senso de autoeficácia decorrente do trabalho realizado. Buscou-se com isso identificar que aspectos da relação professor-aluno, como as suas crenças acerca do aluno e da sua própria experiência com ele, repercutem na sua prática. O que facilita este processo? O que impede? Estas são algumas das questões que este estudo procura responder.

\section{Método}

\section{Delineamento e participantes}

Trata-se de um estudo de caso único (Yin, 2005), no qual participou a educadora de uma escola privada de educação infantil, com formação superior em pedagogia e especialização em psicopedagogia, responsável pela turma frequentada por uma criança com autismo. A educadora estava formada há dois anos, época em que começou a trabalhar nesta escola. 
A escola era de pequeno porte, instalada em uma casa de alvenaria de construção mais antiga. $\mathrm{Na}$ entrada havia uma pequena sala onde funcionava a recepção e em outra sala a secretaria. Havia também três quartos onde funcionava, em cada um deles, um berçário, uma sala de aula e o refeitório. Além disso, também tinha uma cozinha e dois banheiros. No sótão da casa havia dois cômodos que funcionavam como salas de aula para as crianças maiores. O pátio era amplo, com árvores, areia e brinquedos como balanços e um escorregador.

$\mathrm{Na}$ época da coleta de dados eram atendidas, aproximadamente, 15 crianças. O quadro de pessoal era formado por uma pedagoga, que também exercia a função de diretora e cuidava da organização geral da escola (como cozinhar, comprar materiais, etc.) e duas professoras.

\section{Instrumentos}

Entrevista sobre crenças e senso de autoeficácia da educadora. Com base na literatura, foi desenvolvido um questionário específico para a realização da entrevista, com questões semidirigidas e que teve como eixos norteadores: conhecimento sobre o autismo; sentimentos em relação ao trabalho; práticas utilizadas; percepção sobre o desenvolvimento e aprendizagem da criança, bem como sobre o apoio e/ou orientação recebidos. A entrevista com a professora foi realizada pela própria pesquisadora.

\section{Procedimentos de coleta de dados}

Contato inicial e entrevista com a educadora. Após os esclarecimentos quanto à natureza e objetivo do estudo e o consentimento da escola, a educadora responsável pela turma da criança com autismo foi contatada e convidada a participar do estudo, sendo prestados os devidos esclarecimentos sobre o mesmo. Após a assinatura do Termo de Consentimento Livre e Esclarecido (TCLE), agendou-se a entrevista, a qual foi realizada na própria escola. Esta entrevista foi gravada e posteriormente transcrita para análise.

\section{Procedimentos de análise dos dados}

Os dados da entrevista foram analisados através de Análise de Conteúdo (Bardin, 1977), com base em categorias a priori, extraídas da literatura, e em categorias empíricas, geradas pelos dados do estudo.

\section{Considerações éticas}

Conforme a Norma Operacional № 001/2013 do Conselho Nacional de Saúde, os procedimentos desta investigação representaram risco mínimo ao participante, uma vez que não esteve sujeito a atividades invasivas ou privativas de benefício. Este estudo foi submetido ao Sistema CEP/CONEP (Comitê de Ética em Pesquisa e Comissão Nacional de Ética em Pesquisa) e aprovado.

\section{Resultados e discussão}

A entrevista realizada com a educadora, estruturada a partir de um questionário previamente desenvolvido com questões semidirigidas, teve como eixos norteadores: conhecimento sobre o autismo; sentimentos em relação ao trabalho; práticas utilizadas; percepção sobre o desenvolvimento e aprendizagem da criança; e apoio e/ou orientação recebidos. Com base nestes eixos e na literatura, foram geradas, a priori, seis categorias para a análise da entrevista e, a partir desta análise, foram geradas subcategorias empíricas, apresentadas na Tabela 1.

\section{Categorias e subcategorias sobre as crenças e o senso de autoeficácia da educadora}

Autismo. Esta categoria agrupa respostas sobre o conhecimento e as informações que a educadora tem sobre o autismo e modos de acesso aos mesmos. Identificou-se um desconhecimento da educadora sobre o autismo e falta de acesso à informação:

No início eu não sabia nada... até então eu não tinha nem ideia do que era. Eu não conhecia, nunca tinha ouvido falar de autismo, nem na TV. (...) Eu li também um livro. Mas aí era mais relatos nesse livro, mas acabei desistindo porque eu não gostei da leitura, eram muitas coisas diferentes, tinham algumas coisas parecidas com o meu aluno, mas muitas parecia que não encaixava com ele. Claro são pessoas diferentes, mas aí eu desisti de ler, aí não li.

A literatura aponta para a premência de que todo educador ou profissional que trabalhe com uma pessoa com autismo tenha conhecimento dessa condição e de suas peculiaridades (Farias, Maranhão, \& Cunha, 2008; Gomes \& Mendes, 2010; Melo \& Ferreira, 2009; Serra, 2009). Porém, muitas vezes, o que é publicado retrata apenas uma tendência de comportamentos de um determinado grupo, que é necessária para fins de diagnóstico nosológico. Nesse caso, o foco é em padrões de 
Tabela 1. Quadro de Categorias e Subcategorias sobre as Crenças e o Senso de Autoeficácia da Educadora.

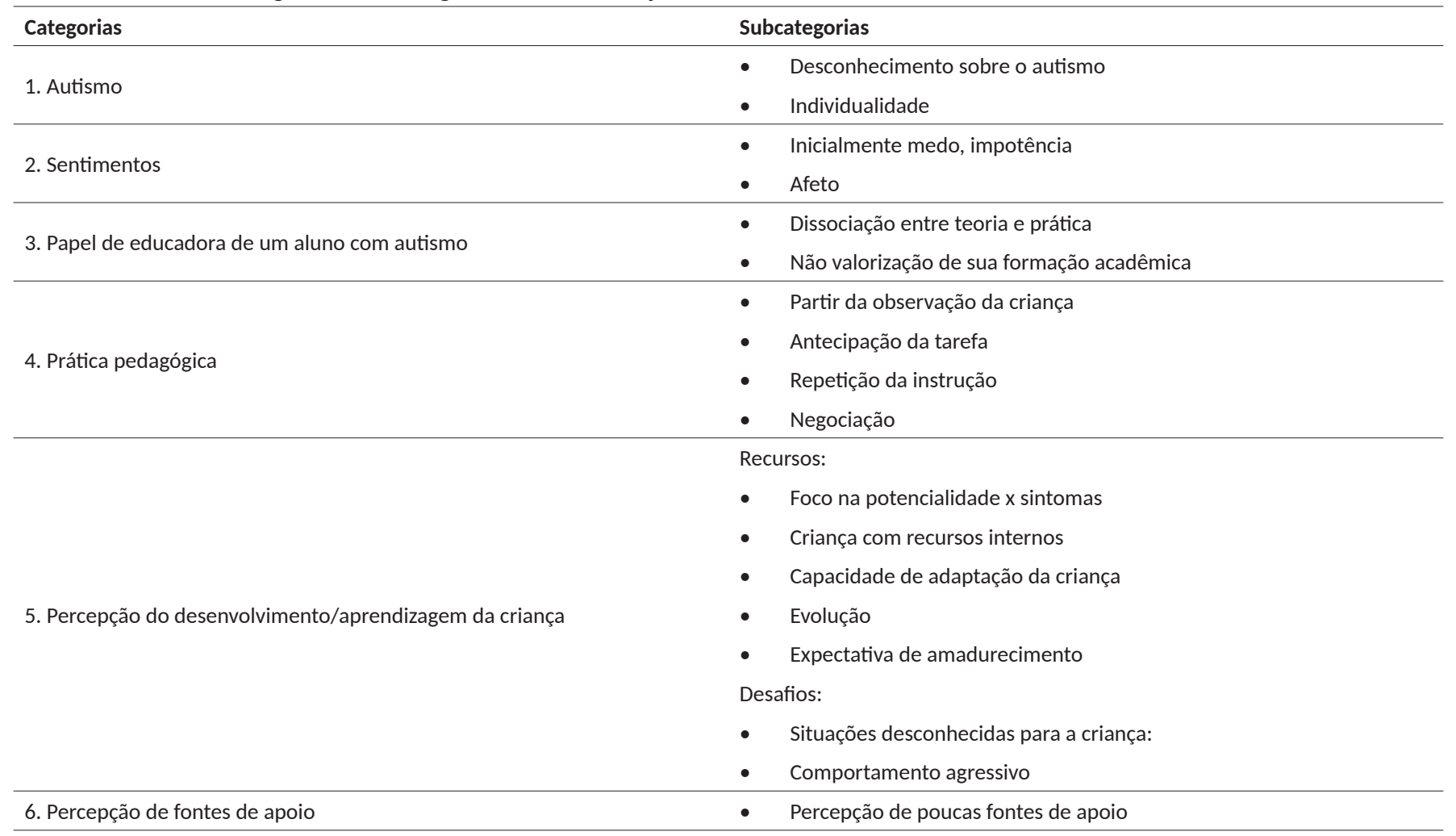

comportamentos que caracterizam uma determinada condição. Na escola, ao contrário, a ênfase deve ser a individualidade de cada criança porque é isto que vai nortear a prática do professor.

A formação teórica não representa todo o universo da prática pedagógica inclusiva. Outros fatores estão elencados neste processo, como a postura pessoal do professor, ou seja, suas convicções, crenças, valores e sensibilidade diante destes alunos (Cacciari et al., 2005; Paiva \& Del Prette, 2009; Robertson et al., 2003). Nesse sentido, o conhecimento teórico precisa estar atrelado à aceitação do aluno, da sua identidade, dos seus avanços tanto quanto dos seus limites.

Sentimentos. Nessa categoria a educadora demonstra o sentimento inicial de medo e impotência ao trabalhar com seu aluno: "... no início eu tinha medo, como é que eu vou lidar com ele, né. De não conhecer mesmo o que é o autismo. (...) Eu pensei: 'Meu Deus, como eu vou trabalhar com ele se nem eu sei'".

A literatura mostra que o sentimento inicial de medo tende a diminuir com o tempo, na medida em que o professor começa a conhecer e a se relacionar com esse aluno, desfazendo, assim, mitos e ideias preconcebidas. Isto permite criar uma relação com a criança e não somente com a "doença" (Monteiro \& Manzini, 2008; Silva
\& Aranha, 2005), postura que facilita a identificação das habilidades e potencialidades da criança e o investimento em seu crescimento e desenvolvimento. No caso da professora deste estudo, na medida em que o trabalho foi sendo realizado ela foi descobrindo a criança que havia ali e o medo cedeu lugar ao carinho, ao afeto e à preocupação genuína com a aprendizagem da criança, como ela refere: "Ah, eu tenho por ele um carinho muito grande, acho que deu pra ti perceber, né. Mas no profissional, aluno e educadora a gente tem um laço afetivo bem forte. Tenho um carinho por ele".

\section{Papel de educadora de um aluno com autismo}

A educadora relata a dificuldade na realização de sua prática pedagógica ao referir: "... eu vou aprendendo no tranco..."; "... eu tenho uma prática, mas o teórico não. $E$, às vezes, a prática é uma coisa e o teórico é outra". Dois aspectos se sobressaem neste relato. O primeiro é a clara dissociação entre a teoria e a prática, e a segunda é a não valorização de sua formação como educadora, pois atribuiu a sua prática ao "acaso" e não a um processo contínuo de atenção cuidadosa à criança, central na formação de todo o educador.

Quanto ao primeiro aspecto observa-se um antagonismo, ao invés de uma integração entre teoria e prá- 
tica, a qual poderia auxiliar no seu trabalho. Verifica-se uma aceitação deste aluno por parte da professora e uma atitude favorável à inclusão do mesmo. No entanto, lhe faltava o conhecimento necessário sobre o autismo para operacionalizar esse processo, aspecto também destacado em outros estudos (Delgado-Pinhero \& Omote, 2010; Lopes \& Crenitte, 2012). Desta forma identificou-se uma tendência a realizar a sua prática com base no método de tentativa e erro, o qual não Ihe ofereceu segurança sobre o quanto o seu trabalho estava sendo adequado para as necessidades desse aluno.

Quanto ao segundo aspecto, chama a atenção que em nenhum momento da entrevista a educadora mencionou sua formação acadêmica ou refletiu sobre as formas de transpor esse conhecimento para sua prática pedagógica atual. Esse dado também é encontrado nos estudos de Martini e Del Prettte (2002) e Tuleski et al. (2005), identificando o baixo senso de autoeficácia demonstrado pelos professores. Esse aspecto merece maior atenção, pois estudos mostram que o conhecimento e as atitudes dos professores, o que inclui seu senso de autoeficácia em relação à inclusão, são preditores de práticas pedagógicas eficazes em sala de aula (Cacciari et al., 2005; Fuller \& Jill, 2006; Goya, Bzuneck, \& Guimarães, 2008; Kuyini \& Desai, 2007; Martins, 2007; Pocinho \& Capelo, 2009).

\section{Prática pedagógica}

As práticas utilizadas para trabalhar com o aluno com autismo foram escolhidas a partir da observação das características da criança, conforme a educadora explica: "... a gente, com a vivência, foi percebendo... pelas características dele... que ele traz". Isso permitiu desenvolver práticas mais adequadas às necessidades da criança, pois foram baseadas no entendimento das situações que ambos vivenciavam. Como ressaltam Melo e Ferreira (2009), ao se cuidar de uma criança é muito importante levar em consideração as suas necessidades, que ao serem respeitadas e atendidas proporcionam importantes informações sobre a qualidade daquilo que é recebido. Para Marocco (2012), a proposta da educação infantil embasa-se no binômio cuidar-educar, sendo estes considerados diferentes aspectos de um mesmo processo.

Algumas práticas que se mostraram úteis em seu trabalho, no ponto de vista da educadora, foram: antecipação da tarefa, a fim de preparar a criança para as mudanças que iriam ocorrer; e a repetição exaustiva das instruções nas situações em que um novo trabalho seria iniciado. No caso do autismo estas são práticas adequadas e necessárias devido, principalmente, às dificuldades na compreensão da linguagem, sobretudo para lidar com sequências complexas de instruções. Nestas ocasiões, para melhor compreensão por parte da criança com autismo, do que Ihe está sendo solicitado ou proposto, é recomendável, por exemplo, que frases muito longas sejam decompostas em unidades menores e apresentadas à criança mais de uma vez (Bosa, 2006). Além disso, esse caráter repetitivo das instruções também pode auxiliar no desenvolvimento da comunicação intencional dessas crianças (Bosa, 2002).

Porém, em algumas situações, mesmo após o uso da repetição da instrução a criança com autismo mostrou-se resistente a essa mudança, reagindo negativamente. Essa dificuldade para mudar o foco de atenção de um padrão de estímulo para outro é bem documentada na literatura sobre os correlatos neuropsicológicos envolvidos nos processos de aprendizagem, tais com a disfunção executiva no autismo (Bosa, 2001; Czermainski, 2012; Lopez, Lincoln, Ozonoff, \& Lai, 2005; Rajendran \& Mitchell, 2007). Essa disfunção envolve, por exemplo, flexibilidade cognitiva, memória e planejamento. A consequência são comportamentos rígidos e perseverativos. Na rotina em sala de aula este aspecto foi evidenciado, por exemplo, na insistência do aluno em fazer um único tipo de desenho, sempre da mesma forma e reagindo negativamente às tentativas da educadora de alterar esta situação. O resultado é um desenho que carece de criatividade e espontaneidade. Contudo, é a forma de expressão que a criança consegue apresentar naquele momento, para fazer "o que os colegas fazem". A educadora reconheceu esta forma singular da criança comportar-se, mas continuou investindo no potencial da criança. Recorreu à negociação, como ela própria relata: "Aí ele ficava brabo, eu dizia: 'Então tá, a profe deixa tu fazer o desenho do tubarão... mas primeiro tu tem que fazer a atividade com a gente'. Aí, ele aceitava, na maioria das vezes ele aceitou".

De fato, conforme a literatura, essa prática pode funcionar com qualquer criança, já que na infância há uma luta por autonomia e pela opção de escolha, que faz parte do desenvolvimento infantil (Vieira, 2009). Dessa forma, a negociação funciona como a antítese da disputa e do desafio, que permite à criança experienciar essa autonomia. No caso do autismo, a simples imposição, sem negociação, pode tornar a criança mais desorganizada. Quando se negocia se está antecipando e disponibilizando à criança pistas a respeito do comportamento 
esperado naquele momento, possibilitando, assim, que ela compreenda o que deve ser feito ao mesmo tempo em que lhe é dada a opção de escolha.

\section{Percepção do desenvolvimento/aprendizagem da criança}

Foram geradas duas subcategorias empíricas: Recursos e Desafios. Quanto aos Recursos, aspectos relacionados à percepção das capacidades da criança com autismo, verifica-se que, antes de tudo, a educadora reconhece seu aluno como uma criança, isto é, a ênfase está na potencialidade e crença no seu desenvolvimento e não no "sintoma". Ela permitiu-se conhecer o seu aluno: suas preferências, necessidades e desejos, identificados como fazendo parte do desenvolvimento e não somente explicados pelo "autismo", conforme ela relata: "... sempre tem alguma coisa, um objeto ou um animal ou alguma coisa que ele gosta muito..."; "... às vezes ele não aceita certas atividades..."; "... com todo mundo ele se dá bem. No início ele não aceitava muito as outras pessoas....".

Essa percepção positiva reforça a relação educadora-aluno, permitindo o reconhecimento de uma criança com recursos internos que, por exemplo, consegue transferir para outro contexto o que aprendeu e modificar padrões de comportamento inicialmente mais rígidos. Um exemplo disso é o desenho, que se tornou mais criativo, conforme a educadora relata:

... às vezes acho que ele se identifica, porque... ele desenhava o tubarão, o golfinho e o caranguejo... e cada um era uma pessoa. Um dia ele me mostrou... o tubarão era ele, o golfinho era a babá dele, e o cavalo- marinho era a mãe dele...

Acreditar que essa criança possui recursos internos para lidar com as situações, permite à educadora investir no desenvolvimento dessa criança, centrando-se em suas potencialidades e, com isso, constatar sua capacidade de adaptação, conforme relatado:

Ele já entrou na rotina da escola, tem uma boa relação tanto com os colegas como com os funcionários... com todo mundo ele se dá bem... No início ele não aceitava muito as outras pessoas, nem os outros professores... Mas agora ele já se adaptou com todo mundo, já entrou no ritmo.

Além disso, a educadora também observa a capacidade de evolução da criança na área da aprendizagem: "A evolução dele é grande... Ele participa, ele faz as atividades, ele faz os trabalhinhos, ele desenvolve".
E deixa clara a expectativa de amadurecimento que possui, tendo um olhar que vai além do estigma das incapacidades e dificuldades quando refere: "Mas eu acho que ele vai crescer muito mais... eu espero que ele cresça mais ainda".

Em relação à subcategoria Desafios, que aborda as dificuldades comportamentais da criança, o que chama a atenção é a percepção da educadora sobre a evolução do aluno quanto às dificuldades apresentadas no início de sua escolarização. Ela destaca a redução na manifestação de comportamentos agressivos:

... no início [quando começou a frequentar a escola] ele se jogava no chão, batia muito com a cabeça na parede... ele era muito agressivo... durante o dia inteiro, várias vezes, ele batia nos colegas, muitas vezes até mordia. Agora já não, ele parou...

A manifestação do comportamento agressivo reflete a desorganização inicial dessa criança frente a uma situação completamente desconhecida, a qual ainda não estava pronta para lidar. Porém, na medida em que a rotina vai se tornando menos ameaçadora por ser mais familiar, tende a ocorrer uma redução nesses problemas. Isso porque a criança passa a ter um senso de controle da situação, ao saber o que se espera dela em cada momento (Bosa, 2001). A literatura tem apontado para a relação existente, no autismo, entre comportamentos agressivos e prejuízos da linguagem e socialização. Alguns estudos mostram que comportamentos desafiadores, como a agressividade, pode ter a função de comunicar algo (e.g. auxílio ou atenção, protesto frustração, provocação dos colegas) que a criança não consegue de outra forma, devido a sua dificuldade na área da comunicação e da linguagem (Catrola, 2010; Miilher \& Fernandes, 2006; Novaes, Pondé, \& Freire, 2008; Silva, Lopes-Herrera, \& De Vitto, 2007).

No momento em que o professor consegue identificar a manifestação do comportamento agressivo do aluno como possivelmente fazendo parte do desenvolvimento infantil e tendo uma função comunicativa importante (Pinho, 2004), ele também consegue responder mais adequadamente a esse comportamento. Esse dado é importante porque, de certa forma, difere daqueles encontrados na literatura, os quais demonstram ser o comportamento agressivo desses alunos umas das principais preocupações dos educadores (Baptista, Vasques, \& Rubleski, 2003). Isso não significa, entretanto, que esses comportamentos sejam mais fáceis de manejar, mas, sim, que a sua compreensão possa gerar ações mais adequadas e sentimentos menos "assustadores". 


\section{Percepção de fontes de apoio}

Quanto ao apoio recebido, a professora relata que a diretora da escola sempre lhe apoiou emocionalmente, disponibilizando-se sempre que necessário para conversar sobre o aluno, sobre os sentimentos experienciados no trabalho realizado e sobre a situação como um todo, sendo a única opção de apoio: "... com a diretora, a gente mais conversava... ela me falou que eu tinha que ter paciência (...). Ela tá sempre me ajudando, ela é quem mais me ajuda, a única pessoa também que tem pra me ajudar".

Além disso, a diretora também forneceu material didático (livro, polígrafos) e disponibilizou-se a realizar encontros semanais com a professora. Tais encontros tinham como objetivo conversar sobre as atividades realizadas com o aluno, suas respostas às mesmas, o comportamento apresentado por ele e os impasses encontrados, além de propor novas tarefas e projetos. Cabe destacar que esta diretora era formada em pedagogia e não possuía formação nem experiência na área do autismo. No entanto, pelo relato da professora verifica-se o seu interesse pelo tema, pelo desenvolvimento do aluno e pela realização de um trabalho sério e voltado, também, para as necessidades desta professora.

De acordo com Orrú (2003), para que a prática docente tome consistência é necessário que os educadores tenham um espaço para se comunicar com seus colegas e/ou com uma equipe de apoio (Silveira, Enumo, \& Rosa, 2012) e, assim, poder partilhar suas ideias, inseguranças, experiências e tentativas. Tais discussões em grupo têm forte relevância para a prática reflexiva do professor. 0 problema é que nesta escola, por ser de pequeno porte, esse espaço de discussão e escuta se restringiu à professora e à diretora, limitando, assim, o compartilhar de diferentes e variadas ideias e sentimentos. Apesar disso, não se pode desmerecer a importância desse momento, mesmo que limitado a duas pessoas, pois permitiu que trocas ocorressem, e à professora a possibilidade de ser ouvida e, ao mesmo tempo, refletir sobre a sua prática.

Para Melo e Ferreira (2009) oportunizar ao professor um espaço de escuta e discussão sobre sua prática e os sentimentos experienciados é uma das estratégias que oferece maior segurança quanto ao trabalho com crianças com necessidades educativas especiais, tornando-o menos angustiante. E quando se trata de alunos com autismo, essa prática se torna mais desafiadora, devido, especialmente, às características comportamentais típicas do autismo, quais sejam: um atraso no funcionamento cognitivo, na maioria dos casos, dificuldades na comunicação - verbal e não-verbal - e nas relações interpessoais (APA, 2013). Tais comportamentos, por si só, já mobilizam muitos sentimentos nos profissionais envolvidos e quando associado à falta de compreensão do motivo de sua ocorrência dificulta ainda mais o trabalho a ser realizado.

Dessa forma, o apoio recebido, apesar de modesto, auxiliou a professora na realização do seu trabalho, conforme ela relata: "... ela [diretora] é quem mais me ajuda, a única pessoa também que tem pra me ajudar". A partir dessa fala também se identifica a necessidade de maior auxílio emocional e instrumental, já que a ajuda sistemática provém de uma única pessoa. Quanto a este aspecto, o que se observou foi uma educadora que constantemente esperou de outrem sugestões e orientações quanto à forma de realizar o seu trabalho: "... eu pergunto pra ela o que que eu faço. Ou eu relato, ele fez isso, fez aquilo, e aí ela me diz, não, tenta agir de outra forma". Isso é preocupante porque a literatura sobre autoeficácia ressalta que este é um recurso pessoal que está relacionado à crença na possibilidade de poder organizar e implementar ações, influenciando a motivação e o bem-estar pessoal no seu trabalho. Esta autonomia pode proteger o professor de experiências de trabalho tensas justamente porque são essas crenças que farão a diferença na forma como a pessoa pensa, sente e age. Desse modo, um dos aspectos fundamentais deste conceito são as expectativas de autoeficácia, pois são estas que determinam quando, quanto e por quanto tempo é necessário o esforço que será empregado nas ações, diante de obstáculos e de experiências frustrantes (Bzuneck \& Guimarães; 2003; laochite, Azzi, Polydoro, \& Winterstein, 2011; Olaz, 2009; Schwarzer \& Hallum, 2008).

\section{Considerações finais}

Em relação às crenças da educadora sobre o autismo e sua influência no trabalho com o aluno foi possível identificar atitudes positivas e de aceitação desta criança. Mesmo com os sentimentos iniciais de medo e insegurança para trabalhar com um aluno "diferente", ela conseguiu desenvolver uma relação baseada no afeto, no carinho e no conhecimento sobre seu jeito de ser e reagir, à medida que a experiência com ele e as orientações que buscou aumentaram.

$\mathrm{O}$ acolhimento e os sentimentos positivos da educadora em relação ao aluno parecem decorrer do vínculo estabelecido, em primeiro lugar, com a criança e não com o autismo. A literatura mostra que optar por 
uma ou outra forma de se vincular com o aluno com necessidades educativas especiais fará muita diferença na prática adotada pelo professor. Permitir que a patologia se sobressaia nessa relação impede a realização de um trabalho efetivo e o reconhecimento das capacidades desse aluno, que acaba sendo visto apenas pelo viés da deficiência. A educadora demonstrou acreditar na capacidade de desenvolvimento de seu aluno, que aliado ao conhecimento sobre o transtorno, as dificuldades, as potencialidades e possibilidades observadas, as metodologias e práticas utilizadas, permitiram um maior investimento na educabilidade deste aluno, no desenvolvimento do trabalho da professora e da confiança na sua capacidade de atuação.

No que se refere ao senso de autoeficácia foi possível identificar, em alguns aspectos, uma baixa expectativa de eficácia por parte da educadora, evidenciada pela pouca valorização de sua formação acadêmica e do conhecimento que possuía para a realização do seu trabalho e pelo sentimento persistente de insegurança em relação à adequação de sua prática, expresso pela necessidade constante de ser reassegurada sobre a qualidade da sua prática.

Mediante estes resultados destaca-se a importância da realização de novos estudos, investigando mais especificamente que fatores estão implicados nessa desvalorização da própria formação e a dificuldade de autonomia para criar e experimentar, ao mesmo tempo em que avalia e reflete sobre a sua prática. Pesquisas com este foco terão implicações para o desenvolvimento de atividades de capacitação de professores da educação infantil que trabalham com esses alunos, permitindo, assim, a construção do conhecimento, a articulação entre teoria e prática e a dissolução de mitos e distorções quanto ao desenvolvimento e à educabilidade de crianças com autismo. Os resultados deste estudo, pelo menos no que refere à educação infantil, parecem inicialmente apontar para a necessidade da formação continuada dos professores, sobretudo daqueles que atuam na área do autismo.

\section{Referências}

Americam Psychiatric Association (2013). Diagnostic and statistical manual of mental disorders ( $5^{\mathrm{a}}$ ed.). Arlington, VA: Americam Psychiatric Publishing.

Bandura, A. (1977). Self-efficacy: Toward a unifyng theory of behavioral change. Psychological Review, 84, 191-215. doi: 10.1037/0033295X.84.2.191
Bandura, A. (1997). Self-efficacy: The exercise of control. Nova lorque: W. H. Freeman.

Baptista, C. R., Vasques, C. K., \& Rublescki, A. F. (2003). Educação e transtornos globais do desenvolvimento: em busca de possibilidades. Cadernos da APPOA, 114, 31-36.

Barcelos, A. M. F. (2006). Cognição de professores e alunos: tendências recentes na pesquisa de crenças sobre ensino e aprendizagem de línguas. In A. M. F. Barcelos \& M. H. Vieira Abrahão (Orgs.), Crenças e ensino de línguas: foco no professor, no aluno e na formação de professores (pp. 15-42). Campinas, Brasil: Pontes.

Bardin, L. (1977). Análise de conteúdo. Lisboa: Edições 70.

Baron-Cohen, S. (1991). Do people with autism understand what causes emotion? Child Development, 62, 385-395. doi: 10.1111/j.14678624.1991.tb01539.x

Bosa, C. A. (2001). As relações entre autismo, comportamento social e função executiva. Psicologia, Reflexão e Crítica, 14(2), 281-287. doi: 10.1590/S0102-79722001000200004.

Bosa, C. A. (2002). Autismo: atuais interpretações para antigas observações. In C. R. Baptista \& C. A. Bosa (Orgs.), Autismo e educação: reflexões e propostas de intervenção (pp. 21-39). Porto Alegre, Brasil: Artmed.

Bosa, C. A. (2006). Autismo: intervenções psicoeducacionais. Revista Brasileira de Psiquiatria, 28, 47-53. doi: 10.1590/S151644462006000500007

Bzuneck, J. A., \& Guimarães, S. E. R. (2003). Crenças de eficácia de professores: validação da escala de Woolfolk e Hoy. PsicoUSF, 8(2), 137-143. doi: 10.1590/S1413-82712003000200005

Bzuneck, J. A., \& Sales, K. F. S (2011). Atribuições interpessoais pelo professor e sua relação com emoções e motivação do aluno. PsicoUSF, 16(3), 307-315. doi: 10.1590/S1413-82712011000300007

Cacciari, F. R., Lima, F. T., \& Bernardi, M. R. (2005). Ressignificando a prática: um caminho para a inclusão. Construção Psicopedagógica, 13, 13-28. Recuperado de http://pepsic.bvsalud.org/scielo. php?script=sci_arttext\&pid=S1415-69542005000100011\&lng=pt \&tlng=pt.

Cardoso, C., \& Fernandes, F. D. M. (2006). Relação entre os aspectos sócio cognitivos e perfil funcional da comunicação em um grupo de adolescentes do espectro autístico. Pró-Fono Revista de Atualização Científica, 18(1), 89- 98. doi: 10.1590/S0104-56872006000100011

Catrola, M. (2010). Aprender com os outros: uma estratégia para a inclusão de um aluno com autismo. Revista Lusófona de Educação, 16, 182-183. Recuperado de http://www.scielo.mec.pt/scielo. php?script=sci_arttext\&pid=S1645-72502010000200030\&lng=pt \&tlng=pt.

Czermainski, F. R. (2012). Avaliação neuropsicológica das funções executivas no transtorno do espectro do autismo (Dissertação de Mestrado). Universidade Federal do Rio Grande do Sul, Porto Alegre. Recuperado de https://www.lume.ufrgs.br/bitstream/ handle/10183/63201/000860693.pdf?sequence=1

De Vitta, F. C. F., De Vitta, A., \& Monteiro, A. S. R. (2010). Percepção de professores de educação infantil sobre a inclusão da criança com deficiência. Revista Brasileira de Educação Especial, 16(3), 415-428. doi: 10.1590/S1413-65382010000300007

Delgado-Pinheiro, E. M. C., \& Omote, S. (2010). Conhecimentos de professores sobre perda auditiva e suas atitudes frente à inclusão. Revista CEFAC, 12(4), 633-640. doi: 10.1590/S1516-18462010005000024. 
Farias, I. M., Maranhão, R. V. A., \& Cunha, A. C. B. (2008). Interação professor-aluno com autismo no contexto da educação inclusiva: análise do padrão de mediação do professor com base na teoria da Experiência de Aprendizagem Mediada (Mediated Learning Experience Theory). Revista Brasileira de Educação Especial, 14(3), 365-384. doi: 10.1590/S1413-65382008000300004

Miilher, L. P., \& Fernandes, F. M. (2006). Análise de funções comunicativas expressas por terapeutas e pacientes do espectro autístico. Pró-Fono - Revista de Atualização Cientifica, 18(3), 239-248. doi: 10.1590/ S0104-56872006000300003

Fuller, R., \& Jill, E. (2006). Age-related changes in the social inclusion of children with autism in general education classrooms. Dissertation Abstracts International Section A: Humanities and Social Sciences, 66(7-A), 2493.

Goldberg, K. (2002). A percepção do professor acerca do seu trabalho com crianças portadoras de autismo e síndrome de Down: um estudo comparativo (Dissertação de mestrado). Universidade Federal do Rio Grande do Sul, Porto Alegre. Recuperado de http://hdl.handle. net/10183/5434

Gomes, C. G. S., \& Mendes, E. G. (2010). Escolarização inclusiva de alunos com autismo na rede municipal de ensino de Belo Horizonte. Revista Brasileira de Educação Especial, 16(3), 375-396. doi: 10.1590/S1413-65382010000300005

Goya, A., Bzuneck, J. A., \& Guimarães, S. E. R. (2008). Crenças de eficácia de professores e motivação de adolescentes para aprender física. Psicologia Escolar e Educacional, 12(1), 51-67. doi: 10.1590/ S1413-85572008000100005.

Höher-Camargo, S. (2007). Interação social com pares, inclusão escolar e autismo: Um estudo de caso comparativo (Dissertação de Mestrado não publicada). Universidade Federal do Rio Grande do Sul, Porto Alegre.

laochite, R. T., Azzi, R. G., Polydoro, S. A. J., \& Winterstein, P. J. (2011). Autoeficácia docente, satisfação e disposição para continuar na docência por professores de educação física. Revista Brasileira de Ciência do Esporte, 33(4), 825-839. doi: 10.1590/S010132892011000400003

Klin, A. (2006). Autismo e síndrome de Asperger: uma visão geral. Revista Brasileira de Psiquiatria, 28, 3-11. doi: 10.1590/S151644462006000500002

Kuyini, A. B., \& Desai, I. (2007). Principals' and teachers' attitudes and knowledge of inclusive education as predictors of effective teaching practices in Ghana. Journal of Research in Special Educational Needs, 7(2), 104-113. doi: 10.1111/j.1471-3802.2007.00086.x

Lopes, R. C. F., \& Crenitte, P. A.P.(2012). Estudo analítico do conhecimento do professor a respeito dos distúrbios de aprendizagem. Revista CEFAC, 15(5), 1214-1226. doi: 10.1590/S1516-18462012005000091

Lopes-Herrera, S. A., \& Almeida, M. A. (2008). O uso de habilidades comunicativas verbais para aumento da extensão de enunciados no autismo de alto funcionamento e na Síndrome de Asperger. PróFono Revista de Atualização Científica, 20(1), 37-42. doi: 10.1590/ S0104-56872008000100007

Lopez, B. R., Lincoln, A. J., Ozonoff, S., \& Lai, Z. (2005). Examining the relationship between executive functions and restricted, repetitive symptoms of autistic disorder. Journal of Autism and Developmental Disorders, 35(4), 445-460. doi: 10.1007/s10803-005-5035-x

Marocco, V. (2012). Sujeitos com autismo em relações: educação e modos de interação (Dissertação de Mestrado). Universidade Federal do Rio Grande do Sul, Porto Alegre. Recuperado de http:// hdl.handle.net/10183/40490
Martini, M. L., \& Del Prette, Z. A. P. (2002). Atribuições de causalidade para o sucesso e o fracasso escolar dos seus alunos por professoras do ensino fundamental. Interação (Curitiba), 6(2), 149-156. doi: 10.5380/psi.v6i2.3302

Martins, M. R. R. (2007). Inclusão de alunos autistas no ensino regular: concepções e práticas pedagógicas de professores regentes (Dissertação de Mestrado). Universidade Católica de Brasília, Brasília. Recuperado de http://www.bdtd.ucb.br/tede/tde_busca/ arquivo.php?codArquivo $=692$

Melo, F. R. L. V., \& Ferreira, C. C. A. (2009). O cuidar do aluno com deficiência física na educação infantil sob a ótica das professoras. Revista Brasileira de Educação Especial, 15(1), 121-140. doi: 10.1590/S1413-65382009000100009.

Monteiro, A. P. H., \& Manzini, E. J. (2008). Mudanças nas concepções do professor do ensino fundamental em relação à inclusão após a entrada de alunos com deficiência em sua classe. Revista Brasileira de Educação Especial, 14(1), 35-52. doi: 10.1590/S141365382008000100004

Moreira, V., \& Monteiro, D. C. (2010). O uso de instrumento e procedimentos de pesquisa sobre crenças: promovendo formação reflexiva. Trabalhos em Linguistica Aplicada, 49 (1), 205-221. doi: 10.1590/ S0103-18132010000100014

Murray, D. S., Ruble, L. A., Willis, H., \& Molloy, C. A. (2009). Parent and teacher report of social skills in children with autism spectrum disorders. Language, Speech, and Hearing Services in Schools, 40, 109-115. doi: 10.1044/0161-1461(2008/07-0089

Musis, C. R., \& Carvalho, S. P. (2010). Representações sociais de professores acerca do aluno com deficiência: a prática educacional e o ideal do ajuste à normalidade. Educação \& Sociedade, 31(110), 201-217. doi: 10.1590/S0101-73302010000100011

Novaes, C. M., Pondé, M. P., \& Freire, A. C. C. (2008). Controle da agitação psicomotora e agressividade em pacientes com autismo: estudo retrospectivo de revisão de prontuário. Arquivos de Neuro-Psiquiatria, 66(3b), 646-651. doi: 10.1590/S0004-282X2008000500008

Olaz, F. O. (2009). Contribuições da teoria social-cognitiva de Bandura para o treinamento de habilidades sociais. In A. Del Prette \& Z. A. P. Del Prette (Orgs.), Psicologia das Habilidades sociais: diversidade teórica e suas implicações (pp. 109-148). Petrópolis, RJ: Vozes.

Orrú, S. E. (2003). A formação de professores e a educação de autistas. Revista Iberoamericana de Educación, 31, 01-15. Recuperado de http://www.rieoei.org/deloslectores/3910rru.pdf

Paiva, M. L. M. F., \& Del Prette, Z. A. P. (2009). Crenças docentes e implicações para o processo de ensino-aprendizagem. Psicologia Escolar e Educacional, 13(1), 75-85. doi: 10.1590/S1413-85572009000100009

Pinho, L. F. S. V. (2004). A agressividade e os conflitos nas brincadeiras entre crianças em situação de risco social (Tese de Doutorado). Universidade Católica de Goiás, Goiás. Recuperado de http://tede. biblioteca.ucg.br/tde_arquivos/11/TDE-2006-08-22T065529Z-196/ Publico/Luiz\%20Fernando\%20Sempionato\%20Vieira\%20Pinho.pd

Pocinho, M., \& Capelo, M. R. (2009). Vulnerabilidade ao stress, estratégias de coping e autoeficácia em professores portugueses. Educação e Pesquisa, 35(2), 351-367. doi: 10.1590/S151797022009000200009

Rajendran, G., \& Mitchell, P. (2007). Teorias cognitivas do autismo. Developmental Review, 27(2), 224-226. doi: 10.1016/j.dr.2007.02.001

Robertson, K., Chamberlain, B., \& Kasari, C. (2003). General education teachers' relationships with included students with autism. Journal of Autism and Developmental Disorders, 33(2), 123-130. doi: 10.1023/A:1022979108096 
Sadalla, A. M. F. A., Wisnivesky, M., Saretta, P., Paulucci, F. C., Vieira, C.P., \& Marques, C. A. E. (2005). Partilhando formação, prática e dilemas: uma contribuição ao desenvolvimento docente. Psicologia Escolare Educacional, 9(1), 71-86. doi: 10.1590/S1413-85572005000100007

Sanini, C., Ferreira, G. D., Souza, T. S., \& Bosa, C. A. (2008). Comportamentos indicativos de apego em crianças com autismo. Psicologia: Reflexão e Crítica, 21(1), 60-65. doi: 10.1590/S010279722008000100008

Sanini, C., Sifuentes, M., \& Bosa, C. A. (2013). Competência social e autismo: o papel do contexto da brincadeira com pares. Psicologia: Teoria e Pesquisa, 29(1), 99-105. doi: 10.1590/S010237722013000100012

Scheifer, C. L. (2009). Ensino de língua estrangeira para crianças - entre o todo e a parte: uma análise da dinâmica das crenças de uma professora e de seus alunos. Trabalhos em Linguistica Aplicada, 48(2), 197-216. doi: 10.1590/S0103-18132009000200003.

Schwarzer, R., \& Hallum, S. (2008). Perceived teacher self-efficacy as a predictor of job stress and burnout: Mediation analyses. Applied Psychology: An International Review, 57, 152-171. doi: http://dx.doi. org/10.1111\%2fj.1464-0597.2008.00359.x

Serra, D. C. G. (2009). Entre a esperança e o limite: um estudo sobre a inclusão de alunos com autismo em classes regulares. Psicologia Clínica, 21(2), 488. doi: 10.1590/S0103-56652009000100017
Silva, R. A., Lopes-Herrera, S. A., \& De Vitto, L. P. M. (2007). Distúrbio de linguagem como parte de um transtorno global do desenvolvimento: descrição de um processo terapêutico fonoaudiológico. Revista da Sociedade Brasileira de Fonoaudiologia, 12(4), 322-328. doi: 10.1590/S1516-80342007000400012

Silva, R. C. (2003). Uma reflexão sobre o trabalho docente a partir da análise do conceito de crença. Psicologia, Ciência e Profissão, 23(2), 6-13. Recuperado de http://pepsic.bvsalud.org/scielo.php?script=sci_ arttext\&pid=S1414-98932003000200003\&lng=pt\&tlng=pt

Silva, S. C., \& Aranha, M. S. F. (2005). Interação entre professora e alunos em salas de aula com proposta pedagógica de educação inclusiva. Revista Brasileira de Educação Especial, 11(3), 373-394 doi: 10.1590/S1413-65382005000300005

Silveira, K. A., Enumo, S. R. F., \& Rosa, E. M. (2012). Concepções de professores sobre inclusão escolar e interaçoes em ambiente inclusivo: uma revisão da literatura. Revista Brasileira de Educação Especial, 18(4), 695-708. doi: 10.1590/S1413-65382012000400011

Tuleski, S.C., Eidt, N. M., Menechinni, A. N., Silva, E. F., Sponchiado, D., \& Colchon, P.D. (2005). Voltando o olhar para o professor: a psicologia e pedagogia caminhando juntas. Revista do Departamento de Psicologia - UFF, 17(1), 129-137. doi: 10.1590/S0104-80232005000100010

Vieira, A. M. (2009). Autoridade e autonomia: uma relação entre a criança e a família no contexto infantil. Revista Iberoamericna de Educación, 49(5), 1-10. Recuperado de http://www.rieoei.org/ deloslectores/2964Morais.pdf

Yin, R. K. (2005). Estudo de caso: planejamento e métodos (D. Grassi, Trad., $3^{\mathrm{a}}$ ed.). Porto Alegre, Brasil: Bookman/Artes Médicas.
Cláudia Sanini, Doutora em Psicologia pela Universidade Federal do Rio Grande do Sul, é Professor Convidado na Universidade Federal do Rio Grande do Sul. Endereço para correspondência: Av. Alberto Bins, 820/1101 - Centro - Porto Alegre/RS, CEP 90030-141. Telefones: (51) 3022-4910; (51) 9893-8135;

(54) 9969 2922. E-mail: claudiasanini@gmail.com

Cleonice Alves Bosa, Doutora em Psicologia pelo Instituto de Psiquiatria pela Universidade de Londres (UK), Pós-doutora pelo Cincinnatti Childrens Mecial Hospital, Ohio (USA), é Professora Associada na Universidade Federal do Rio Grande do Sul. E-mail: cleobosa@uol.com.br 